\title{
XXIII. Account of a series of experiments, showing the effects of compression in modifying the action of heat
}

\section{Sir James Hall Bart. F.R.S.}

To cite this article: Sir James Hall Bart. F.R.S. (1806) XXIII. Account of a series of experiments, showing the effects of compression in modifying the action of heat, Philosophical Magazine Series 1, 25:98, 143-157, DOI: 10.1080/14786440608563424

To link to this article: http://dx.doi.org/10.1080/14786440608563424

曲 Published online: 18 May 2009.

Submit your article to this journal $\pi$

Џll Article views: 4

Q View related articles $\sqsubset$ 
XXIII. Account of a Series of Experiments, showing the Effects of Compression in modifying the Action of Heat. By Sir James Haxl, Bart. F.R.S. Lond. and Edin.

[Continued from p. 26.]

\section{$\S$ VII.}

Measurement of the Force required to constrain the Carbonic Acid.-Apparatus with the Muzzle of the Barrel upwards, and the Weight asting by a long Lever.-Apparatus with the Muzzle downwards.-Apparatus with Weight acting directly on the Barrel.-Comparison of various Results.

$I_{\mathbf{N}}$ order to determine, within certain limits at least, what force had been exerted in the foregoing experiments, and what was necessary to ensure their success, I made a number of experiments in a mode nearly allied to that followed by Count Rumford in measuring the explosive force of gunpowder.

I began to use the following simple apparatus in June 1803 :-I took one of the barrels, made as above described, for the purpose of compression, having a bore of 0.75 of an inch*, and dressed its muzzle to a sharp edge. To this barrel was firmly screwed a collar of iron ( $a a$, fig. 36) placed at a distance of about three inches from the muzzle, having two strong bars $(b b)$ projecting at right angles to the barrel, and dressed square. The barrel, thus prepared, was introduced, with its breech downwards, into the vertical muffle (fig. 35); its length being so adjusted, that its breech should be placed in the strongest heat; the two projecting bars above described resting on two other bars (cc, fig. 35) laid upon the furnace to receive them; one upon each side of the muffle. Into the barrel so placed was introduced a cradle, containing carbonate, with all the arrangements formerly mentioned, the rod connected with it being of such length as just to lie within the nuzzle of the barrel. The liquid metal was then poured in till it filled the barrel, and stood

* This was the size of barrel used in all the following experiments, where the fact is not otherwise expressed. 
at the muzzle with a convex surface; a cylinder of iron, of about an inch in diameter and half an inch thick, was laid on the muzzle (fig. 35 and 37 ), and to it a compressing weight was instantly applied. This was first done by the pressure of a bar of iron (de, fig. 35), three feet in length, introduced loosely into a hole $(d)$, made for the purpose in the wall against which the furnace stood, the distance between this hole and the wall being one foot. A weight was then suspended at the extremity of the bar $(e)$, and thus a compressing force was applied equal to three times that weight. In the course of practice, a cylinder of lead was substituted for that of iron, and a piece of leather was placed between it and the muzzle of the barrel, which last being dressed to a pretty sharp edge, made an impression in the lead: to assist this effect, one smart blow of a hammer was struck upon the bar, directly over the barrel, as soon as the weight had been hung on.

It was essential, in this mode of operation, that the whole of the metal should continue in a liquid state during the action of heat ; but when I was satisfied as to its intensity and duration, I congealed the metal, either by extinguishing the furnace entirely, or by pouring water on the barrel. As soon as the heat began to act, drops of metal were seen to force themselves between the barrel and the leather, following each other with more or less rapidity, according to circumstances. In some experiments there was little exudation; but few of them were entirely free from it. - To save the metal thus extruded, I placed a black lead crucible, having its bottom perforated, round the barrel, and luted close to it (fig. 37); some sand being laid in this crucible, the metal was collected on its surface. On some occasions, a sound of ebullition was heard during the action of heat; but this was a certain sign of failure.

The results of the most important of these experiments have been reduced to a common standard in the second table placed in the Appendix; to which reference is made by the following numbers :

No. 1.-On the 16 th of June 1803 , I made an experiment with these arrangements. I bad tried to use a weight 
of $30 \mathrm{lbs}$. producing a pressure of $90 \mathrm{lbs}$; ; but 1 found this not sufficient. I then hung on a weight of 1 cwt., or $112 \mathrm{lbs} . ;$. by which a compressing force was applied of 3 cwt., or $336 \mathrm{lbs}$. Very little metal was seen to escape, and no sound of ebullition was heard. The chalk in the body of the large tube was reduced to quicklime; but what lay in the inner tube was pretty firm, and effervesced to the last. One or two facettes, of good appearance, were likewise found. The contents of the small tube had lost but $2 \cdot 6$ per cent.; but there was a small visible intrusion of metal, and the result, by its appearance, indicated a greater loss. I considered this, however, as one point gained; that being the first tolerable compression accomplished by a determinate force. The pyrometer indicated $22^{\circ}$.

This experiment was repeated the same day, when a still smaller quantity of metal escaped at the muzzle; but the barrel had given way below, in the manner of those that have yielded for want of sufficient air. Even this result was satisfactory, by showing that a mechanical power, capable of forcing some of the barrels, could now be commanded. The carbonate in the little tube had lost 20 per cent.; but part of it was in a hard and firm state, effervescing to the last.

No. 2.-On the 21 st of June I made an experiment with another barrel, with the same circumstances. I had left an empty space in the large tube, and had intended to introduce its muzzle downwards, meaning that space to answer as an air-tube ; but it was inverted by mistake, and the tube, entering with its muzzle upwards, the empty space had of course filled with metal, and thus the experiment was made without any included air. There was no pyrometer used; but the heat was guessed to be about $25^{\circ}$ where the subject of experiment lay. The barrel, when opened, was found full of metal, and the cradle being laid flat on the table, a considerable quantity of metal ran from it, which had undoubtedly been lodged in the vacuity of the large tube. When cold, I found that vacuity still empty, with a plating of metal. The tube was very clean to appearance, and, when shaken, its contents were heard to rattle. Above the

Vol. 25. No. 98. July 1806. K Jittle 
little tube, and the cylinder of chall- I had put some borax and sand, with a little pure borax ing middle, and chalk over it. The metal had not penetrated beyond the borax and sand, by a good fortune peculiar to this experiment; the intrusion of metal in this mode of execution being extremely troublesome. The button of chalk was found in a state of clean white carbonate, and pretty hard, but without transparency. The liftle tube was perfectly clean. Its weight, with its contents, seemed to have suffered no change from what it had been when first introduced. Attending, however, to the balance with scrupulous nicety, a small preponderance did appear on the side of the weight. This was done away by the addition of the hundredth of a grain to the scale in which the carbonate lay, and an addition of another hundredth produced in it a decided preponderance. Perhaps, had the tube, before its introduction, been examined with the same care, as great a difference might have been detected; and it seems as if there had been no loss, as least not more than one hundredth of a grain, which, on 10.95 grains, amounts to 0.0912 , say 0.1 per cent. The carbonate was loose in the little tube, and fell out by shaking. It had a yellow colour, and compact appearance, with a stony hardness under the knife, and a stony fracture ; but with very slight facettes, and little or no transparency. In some parts of the specimen, a whitish colour seemed to indicate partial calcination. On examining the fracture, I perceived, with the magnifier, a small globule of metal, not visible to the naked eye, quite insulated and single. Possibly the substance may have contained others of the same sort, which may have compensated for a small loss; but there could not be many such, from the general clean appearance of the whole. In the fracture, I saw here and there small round holes, seeming, though imperfectly, to indicate a beginning of ebullition.

I made a number of experiments in the same manner, that is to say, with the muzzle of the barrel upwards, in some of which I obtained very satisfactory results; but it was only by chance that the substance escaped the contamination of the fusible metal; which induced me to think 
of another mode of applying the compressing weight with the muzzle of the barrel downwards, by which I expected to repeat, with a determinate weight, all the experiments formerly made in barrels closed by congealed metal; and that, by making use of an air-tube, the air, rising to the breech, would secure the contents of the tube from any contamination. In this view, the barrel was introduced from below into the muffle with its breech upwards, and retained in that position by means of a hook fixed to the furnace, till the collar was made to press up against the grate, by an iron lever, loaded with a weight, and resting on a support placed in front. In some experiments made in this way, the result was obtained very clean, as had been expected; but the force had been too feeble, and when it was increased, the furnace yielded upwards by the mechanical strain.

I found it therefore necessary to use a frame of iron (as in fig. 38, the frame being represented separately in fig. 39), by which the brick-work was relieved from the mechanical strain. This frame consisted of two bars $(a b$ and $f e$, figs. 38 and 39), fixed into the wall (at $a$ and $f$ ), passing horizontally under the furnace, one on each side of the muffle, turning downwards at the front (in $l$ and $e$ ), and meeting at the ground, with a flat bar $(c d)$ uniting the whole. In this manner, a kind of stirrup $(b c d e)$ was formed in front of the furnace, upon the cross bar $(c d)$ of which a block of wood ( $h h$, fig. 38) was placed, supporting an edge of iron, upon which the lever rested, the working end of the lever $(g)$ acting upwards. A strain was exerted, by means of the barrel and its collar, against the hibrizontal bars $(a b$ and $f e$ ), which was effectually resisted by the wall (at $a$ and $f$ ) at one end of these bars, and by the upright bars ( $c l$ and $d e$ ) at the other end. In this manner the whole strain was sustained by the frame, and the furnace stood without injury.

The iron bar, at its working end, was formed into the shape of a cup (at $g$ ), and half filled with lead, the smooth surface of which was applied to the muzzle of the barrel. The lever, too, was lengthened, by joining to the bar of iron a beam of wood, making the whole ten feet in length. 
In this manner, a pressure upwards was applied to the barrel equal to the weight of $10 \mathrm{cwt}$.

In the former method, in which the barrel stood with its muzzle upwards, the weight was applied while the metal was liquid. In this case it was necessary to let it previously congeal, otherwise the contents would have run out in placing the barrel in the maffle, and to allow the liquefaction essential to these trials to be produced by the propagation of heat from the mufle downwards. This method required, therefore, in every case the use of an air-tube ; for, without it, the heat acting upon the breech, while the metal at the muzzle was still cold, would infallibly have destroyed the barrel. A great number of these experiments failed, with very considerable waste of the fusible metal, which on these occasions was nearly all lost. But a few of them succeeded, and afforded very satisfactory results, which I shall now mention.

In November 1803, some good experiments were made in this way, all with a bore of 0.75 , and a pressure of 10 cwt.

No. 3.-On the 19 th a good limestone was obtained in an experiment made in a temperature of $21^{\circ}$, with a loss of only 1.1 per cent.

No. 4. On the $22 \mathrm{~d}$, in a similar experiment, there was little exudation by the muzzle. The pyrometer gave $31^{\circ}$. The carbonate was in a porous and almost frothy state.

No. 5.-In a second experiment, made the same day, the heat rose to $37^{\circ}$ or $41^{\circ}$. The substance bore strong marks of fusion, the upper part having spread on the little tube : the whole was very much shrunk, and run against one side. The mass sparkling and white, and in a very good state.

No. 6.-On the 25 th an experiment was made with chalk and some fragments of snail shell, with about half a grain of water. The heat had risen to near $51^{\circ}$ or $49^{\circ}$. The barrel had been held tight by the beam, but was rent and a little swelled at the breech. The rent was wide, and such as has always appeared in the strongest barrels when they failed. The carbonate was quite calcined; it had boiled over the little tube, and was entircly in a frothy state, with large 
and distinctly rounded air-holes. The fragments of shell, which had occupied the upper part of the little tube, had lost every trace of their original shape in the act of ebullition and fusion.

No. 7.-On the 26 th a similar experiment was made, in which the barrel was thrown open, in spite of this powerful compressing force, with a report like that of a gun (as I was told, not having been present), and the bar was found in a state of strong vibration. The carbonate was calcined, and somewhat frothy; the heart of one piece of chalk used was in a state of saline marble.

It now occurred to me to work with a compressing force, and no air-tube, trusting, as happened accidentally in one case, that the expansion of the liquid would clear itself by gentle exudation, without injury to the carbonate. In this mode it was necessary, for reasons lately stated, to place the muzzle upwards. Various trials made thus, at this time, afforded no remarkable results. But I resumed the method, with the following alteration in the application of the weight, on the 27th of April 1804.

I conceived that some inconvenience might arise from the mode of employing the weight in the former experiments. In them it had heen applied at the end of the bar', and its effect propagated along it, so as to press against the barrel at its other extremity. It occurred to me, that, the propagation of motion in this way requiring some sensible time, a considerable quantity of carbonic acid might escape, by a sudden eruption, before that propagation, had taken effect. I therefore thought that more effectual work might be done by placing a heavy mass (fig. 40) so as to act directly and simply upon the muzzle of the barrel; this mass being guided and commanded by means of a powerful lever $(a b)$. For this purpose I procured an iron roller, weighing $3 \mathrm{cwt}$. $7 \mathrm{lbs}$., and suspended it over the furnace to the end of a beam of wood, resting on a support near the furnace, with a long arm guided by a rope $(c c)$ and pulley $(d)$, by which the weight could be raised or let down at pleasure.

With this apparatus I made some tolerable experiments; but $I$ found the weight too light to afford certain and steady K 3 results 
results of the best quality. I therefore procured at the foundry a large mass of iron $(f)$, intended, I believe, for driving piles, and which, after allowing for the counterpoise of the beam, gave a direct pressure of $8.1 \mathrm{cwt}$.; and I could, at pleasure, diminish the compressing force, by placing a bucket $(e)$ at the extremity of the lever, into which $I$ introduced weights, whose effect on the ultimate great mass was known by trial. Many barrels failed in these trials : at last I obtained one of small bore, inch 0.54 , which gave two good results on the $22 \mathrm{~d}$ of June 1804 .

No. 8.-Wishing to ascertain the least compressing force by which the carbonate could be effectually constrained in melting heats, I first observed every thing standing firm in a heat of above $20^{\circ}$; I then gradually threw weights into the bucket, till the compressing force was reduced to $2 \mathrm{cwt}$. Till thell, things continued steady; but, on the pressure being still further diminished, metal began to onze out at the muzzle with increasing rapidity. When the pressure was reduced to $1 \frac{1}{2} \mathrm{cwt}$. air rushed out with a hissing noise. I then stopped the experiment, by pouring water on the barrel. The piece of chalk had lost 12 per cent. It was white and soft on the outside, but firm and good in the heart.

No. 9.-An experiment was made with chalk, in a little tube; to this, one grain of water was added. I had intended to work with $4 \mathrm{cwt}$. only; but the barrel was no sooner placed, than an exudation of metal began at the muzzle, owing, doubtless, to the elasticity of the water. I immediately increased the pressure to $8.1 \mathrm{cwt}$. by removing the weight from the bucket; when the exudation instantly ceased. I continued the fire for three quarters of an hour, during which time no exudation happened; then all came out remarkably clean, with scarcely any contamination of metal. The loss amounted to $2: 58$ per cent. The substance was tolerably indurated, but had not acquired the character of a complete stone.

In these two last experiments, the bore being small, a pyrometer could not be admitted.

On the 5th of July 1804, I made three very satisfactory experiments 
experiments of this kind, in a barrel with the large bore of 0.75 of an inch.

No. 10. was made with a compressing force of only $3 \mathrm{cwt}$. A small eruption at the muzzle being observed, water was thrown on the barrel: the pyrometer gave $21^{\circ}$ : the chalk was in a firm state of limestone.

No. 11. with $4 \mathrm{cwt}$. The barrel stood, without any eruption or exudation, till the heat rose to $25^{\circ}$. There was a loss of $\mathbf{3 . 6}$ per cent.: the result was superior, in hardness and transparency, to the last, having somewhat of a saline fracture.

No. 12. with $5 \mathrm{cwt}$. The result, with a loss of $2 \cdot 4$ per cent., was of a quality superior to any of those lately obtained.

These experiments appear to answer the end proposed, of ascertaining the least pressure, and lowest heat, in which limestone can be formed. The results, with various barrels of different sizes, agree tolerably, and tend to confirm each other. The table shows, when we compare Nos. 1, 2, 8, $10,11,12$, that a pressure of 54 atmospheres, or 1700 feet of sea, is capable of forming a limestone in a proper heat : that under $\mathbf{8 6}$ atmospheres, answering nearly to 3000 feet, or about half a mile, a complete marble may be formed: and lastly, that with a pressure of 173 àtmospheres, or 5700 feet, that is, little more than one mile of sea, the carbonate of lime is made to undergo complete fusion, and to act powerfully on other earths.

\section{$\S$ VIII.}

Formation of Coal.-Accidental Occurrence which led me to undertake these Experiments.-Results extracted from a former Publication.-Explanation of some Difficulties that have leen suggested.-The Filres of Wood in some Cases obliterated, and in some preserved, under Compression.Resemblance which these Results bear to a Series of $\mathrm{Na}$ tural Sulstances described by Mr. Hatchett.-These Results seem to throw Light on the History of Surturbrand.

As I intend, on some future occasion, to resume my experiments with inflammable substances, which I look upon

K 4 
as far from complete, I shall add but a few observations to what I have already laid before this society, in the sketch I had the honour to read in this place on the 30th of August last.

The following incidental occurrence led me to enter upon this subject rather prematurely, since I had determined first to satisfy myself with regard to the carbonate of lime.

Observing, in many of the last-mentioned class of experiments, that the elastic matters made their escape between the muzzle of the barrel and the cylinder of lead, I was in the habit, as mentioned above, of placing a piece of leather between the lead and the barrel ; in which position, the heat to which the leather was exposed was necessarily below that of melting lead. In an experiment, made on the 28th November 1803 , in order to ascertain the power of the machinery, and the quantity of metal driven out by the expansion of the liquid, there being nothing in the barrel but metal, I observd, as soon as the compressing apparatus was removed, (which on this occasion was done while the lower part of the barrel was at its full heat, and the barrel standing brim full of liquid metal,) that all the leather which lay on the outside of the circular muzzle of the barrel remained, being only a little browned and crumpled by the heat to which it had been exposed. What leather lay within the circle, had disanpeared; and, on the surface of the liquid metal, which stood up to the lip of the barrel, I saw large drops of a shining black liquid, which, on cooling, fixed into a crisp black substance, with a shining fracture, exactly like pitch or pure coal. It burned, though not with flame. While hot, it smelt decidedly of volatile alkali. The important circumstance here, is the different manner in which the heat has acted on the leather, without and within the rim of the barrel. The only difference consisted in compression, to which, therefore, the difference of effect must be ascribed: by its force, the volatile matter of the leather which escaped from the outward parts, had within the rim been constrained to remain united to the rest of the composition, upon which it had acted as a flux, and the whole together had entered into a liquid state, in a very low heat. 
Had the pressure been continued till all was cool, these substances must have been retained, producing a real coal.

On the 24th of April 1803, a piece of leather used in a similar manner (the compressing force being continued, however, till all was cold) was changed to a substance like glue, owing doubtless to compression, in a heat under that of melting lead.

These observations led me to make a series of experiments with animal and vegetable substances, and with coal; the result of which I have already laid before the society. I shall now repeat that communication, as printed in Nicholson's Journal for October last (1804).

"I have likewise made some experiments with coal, treated in the same manner as the carbonate of lime: but I have found it much less tractable; for the bitumen, when heat is applied to it, tends to escape by its simple elasticity, whereas the carbonic acid in marble is in part retained by the chemical force of quicklime. I succeeded, however, in constraining the bituminous matter of the coal, to a certain degree, in red heats, so as to bring the substance into a complete fusion, and to retain its faculty of burning with flame. But I could not accomplish this in heats capable of agglutinating the carbonate; for I have found, where I rammed them successively into the same tube, and where the vessel has withstood the expansive force, that the carbonate has been agglutinated into a good limestone, but that the coal has lost about half its weight, together with its power of giving flame when burnt, remaining in a very compact state, with a shining fracture. Although this experiment has not afforded the desired result, it answers another purpose admirably well. It is known, that where a bed of coal is crossed by a dike of whinstone, the coal is found in a pe. culiar state in the immeriate neighbourbood of the whin; the substance in such places being incapable of giving flame, it is distinguished by the name of blind coal. Dr. Hutton has explained this fact, by supposing that the bituminous matter of the coal has been driven by the local heat of whin into places of less intensity, where it would probably be retained by distillation. Yet the whole must have been car- 
ried on under the action of a pressure capable of constraining the carbonic acid of the calcareous spar, which occurs frequently in such rocks. In the last-mentioned experiment we have a perfect representation of the natural fact; since the coal has lost its petroleum, while the chalk in contact with it has retained its carbonic acid.

"I have made some experiments of the same kind, with vegetable and animal substances. I found their volatility much greater than that of coal, and I was compelled, with them, to work in heats below redness; for, even in the lowest red heat, they were apt to destroy the apparatus. The animal substance I commonly used was horn, and the vegetable, saw-dust of fir. The horn was incomparably the most fusible and volatile of the two. In a very slight heat it was converted into a yellow red substance, like oil, which penetrated the clay tubes through and through. In these experiments $I$ therefore made use of tubes of glass. It was only after a considerable portion of the substance had been separated from the mass that the remainder assumed the clear black peculiar to coal. In this way I obtained coal both from saw-dust and from horn, which yielded a bright flame in burning,

" The mixture of the two produced a substance having exactly the smell of soot or coal tar. I am therefore strongly inclined to believe, that animal substance, as well as vegetable, has contributed towards the formation of our bituminous strata. This seems to confirm an opinion, advanced by $\mathrm{Mr}$. Keir, which has been mentioned to me since 1 made this experiment. I conceive that the coal which now remains in the world is but a small portion of the organic matter originally deposited: the most volatile parts have been driven off by the action of heat before the temperature had risen high enough to bring the surrounding substance into fusion, so as to confine the elastic fluids, and subject them to compression.

" In several of these experiments I found, when the pressure was not great, when equal, for instance, only to eighty atmospheres, that the horn employed was dissipated entirely, the glass tube which had contained it being left 
almost clean; yet undoubtedly, if exposed to heat without compression, and protected from the contact of the atmosphere, the horn would leave a cinder or coke behind it, of matter wholly devoid of volatility. Here, then, it would seem as if the moderate pressure, by keeping the elements of the substance together, had promoted the general volatility, without being strong enough to resist that expansive force, and thus, that the whole had escaped. This result, which I should certainly not have foreseen in theory, may, perhaps, account for the absence of coal in situations where its presence might be expected on principles of general analogy."

Since this publication, a very natural question has been put to me. When the inflammable substance has lost weight, or when the whole bas been dissipated in these experiments, what has become of the matter thus driven off?

I must own, that to answer this question with perfect confidence, more experiments are required. But, in the course of practice, two circumstances have occurred as likely, in most cases, to have occasioned the loss alluded to. I found in these experiments, particularly with horn, that the chalk, both in powder and in lump, which was used to fill vacuities in the tubes, and to fix them in the cradle, was strongly impregnated with an oily or bituminous matter, giving to the substance the qualities of a stinkstone. I conceive that the most volatile part of the horn has been conveyed to the chalk, partly in a state of vapour, and partly by boiling over the lips of the glass tube, the whole having been evidently in a state of very thin fluidity. Having, in some cases, found the tube, which had been introduced full of horn, entirely empty after the experiment, I was induced, as above stated, to conceive, that, under pressure, it had acquired a greater general volatility than it had in freedom; and I find that, in the open fire, horn yields a charcoal equal to 20 per cent. of the original weight. But more experiments must be made on this subject.

Another cause of the loss of weight lay undoubtedly in the excess of heat employed in most of them to remove the cradle from the barrel. With inflammable substances no 
air-tube was used, and, the heats being low, the air lodged in interstices had been sufficient to secure the barrels from destruction by the expansion of the liquid metal. In this view, likewise, I often used lead, whose expansion in such low heats I expected to be less than that of the fusible metal. And the lead requiring to melt it a heat very near to that of redness, the subject of experiment was thus, on removing the cradle, exposed in freedom to a temperature which was comparatively high. But, observing that a great loss was thus occasioned, I returned to the use of the fusible metal, together with my former method of melting it, by plunging the barrel, when removed from the furnace, into a solution of muriate of lime, by which it could only receive a heat of $250^{\circ}$ of Fahrenheit.

The effect was remarkable in the few experiments tried in this way. The horn did not, as in the other experiments, change to a hard black substance, but acquired a semi-fluid and viscid consistency, with a yellow red colour, and a very offensive smell. This shows that the substances which here occasioned both the colour and smell of the results, had been driven off in the other experiments by the too great heat applied to the substance when free from compression.

I found that the organization of animal substance was entirely obliterated by a slight action of heat, but that a stronger heat was required to perform the entire fusion of vegetable matter. This, however, was accomplished; and in several experiments pieces of wood were changed to a jet black and inflammable substance, generally very porous, in which no trace could be discovered of the original organization. In others, the vegetable fibres were still visible, and are forced asunder by large and shining air-bubbles.

Since the publication of the sketch of my experiments I have had the pleasure to read Mr. Hatchett's very interesting account of various natural substances nearly allied to coal, and I could nut help being struck with the resemblance which my results bear to them, through all their varieties, as brought into view by that able chemist; that resemblance affording a presumption, that the changes which, with true scientific modesty, he ascribes to an unknown cause, may 
have resulted from various heats acting under pressure of various force. The substance to which he has given the name of retinasphaltum seems to agree very nearly with what I have obtained from animal substance, when the barrel was opened by means of low heat. And the specimen of wood entering into fusion, but still retaining the form of its fibres, seems very similar to the intermediate substance of Bovey coal and surturbrand, which Mr. Hatchett has assimilated to each other. It is well known that the surturbrand of Iceland consists of the stems of large trees, flattened to thin plates by some operation of nature hitherto unexplained. But the last-mentioned experiment seems to afford a plausible solution of this puzzling phænomenon.

In all parts of the globe we find proofs of slips, and various relative motions, having taken place amongst great masses of rock, whilst they were soft in a certain degree, and which have left unequivocal traces behind them, both in the derangement of the beds of strata. and in a smooth and shining surface, called slickenside, produced by the direct friction of one mass on another. During the action of subterranean heat, were a single stratum to occur, containing trees intermixed with animal substances, shell fish, \&c., these trees would be reduced to a soft and unctuous state, similar to that of the piece of wood in the last-mentioned experiment, whilst the substance of the contiguous strata retained a considerable degree of firmness. In this state of things, the stratum just mentioned would very naturally become the scene of a slip, occasioned by the unequal pressure of the surrounding masses. By such a sliding motion, accompanied by great compression, a tree would be flattened, as any substance is ground in a mortar, by the combination of a fateral and direct force. At the same time the shells along with the trees would be flattened like those described by Bergman, while those of the same species in the neighbouring limestone rock, being protected by its inferior fusibility, would retain their natural shape.

[To be continued.] 